\title{
Composição química e qualidade fisiológica de sementes de girassol de plantas submetidas à competição intraespecífica ${ }^{1}$
}

\author{
Fernanda Vieira Alves ${ }^{2 *}$, Adílio de Sá Junior ${ }^{2}$, Denise Garcia Santana ${ }^{2}$, \\ Carlos Machado dos Santos ${ }^{2}$
}

\begin{abstract}
RESUMO - Avaliou-se a composição química e a qualidade fisiológica de sementes de girassol oriundas de diferentes regiões do capítulo e de plantas-mãe originadas de sementes de alto e baixo vigor que sofreram competição intraespecífica. O delineamento experimental foi em blocos casualizados com quatro repetições, sendo os tratamentos distribuídos em parcelas subdivididas. Nas parcelas avaliaramse cinco proporções de sementes com alto vigor colocadas na linha de semeadura. Nas subparcelas foram avaliadas as plantas oriundas das sementes de cada nível de vigor e dois tratamentos adicionais. Foi realizada análise relacionando-se as proporções de vigor avaliadas e os terços do capítulo. Avaliouse a porcentagem de proteínas, lipídeos, carboidratos totais, cinzas, o grau de umidade, o peso de mil sementes e as medidas de emergência (tempos inicial, final e médio de emergência, velocidades média e de emergência, incerteza, sincronia, coeficiente de variação do tempo e emergência), obtidas pelo teste de emergência em areia. Os resultados indicam que: a proporção de vigor das sementes na linha de semeadura interfere no desempenho das plantas e na qualidade das sementes resultantes; a composição química das sementes de girassol variou com a posição das sementes no capítulo; a posição da semente no capítulo interferiu nas variáveis da germinação.
\end{abstract}

Termos para indexação: vigor de sementes, emergência de plântulas, terços do capítulo, Helianthus annuus L.

\section{Chemical composition and physiological quality of sunflower seeds of plants submitted to intra-specific competition}

\begin{abstract}
The objective of this study was to evaluate the chemical composition and physiological quality of sunflower seeds from different regions of the flowering head and from plants originating from high and low vigor seeds subjected to intra-specific competition. The experimental design was randomized blocks with four repetitions with treatments distributed in split plots. In the plots, five proportions of high vigor seeds sown in furrows were evaluated, whereas in the sub-plots, evaluations were made of the plants originating from high or low vigor seeds and two additional treatments. The relationship between the proportions of high vigor seeds and their position in the flowering heads was evaluated. The percentage of proteins, lipids, total carbohydrates, ashes, moisture content, weight of a thousand seeds and emergence parameters (beginning, middle and final times, mean emergence velocity, uncertainty, synchronicity, coefficients of variation of time and emergence), obtained from the emergence test in sand, were determined. The results indicated that: the proportion of seed vigor in the furrow interferes in plant performance and the resulting seed quality; the chemical composition of the seeds depended on seed position in the flowering head; the position of the seed in the head affected the germination variables.
\end{abstract}

Index terms: seed vigor, seedling emergency, third of head, Helianthus annuus L.

\footnotetext{
${ }^{1}$ Submetido em 25/02/2011. Aceito para publicação em 15/02/2012.

${ }^{2}$ Instituto de Ciências Agrárias, Universidade Federal de Uberlândia, Caixa Postal 593, 38400-902-Uberlândia, MG, Brasil.

*Autor para correspondência <nandavalves@yahoo.com.br>
} 


\section{Introdução}

A versatilidade de uso das sementes de girassol resulta em um gradual aumento de interesse por esta cultura. A demanda mundial por girassol tem aumentado em média $1,8 \%$ por ano. A demanda brasileira por óleo de girassol, estimada em 35 a 45 toneladas, aumenta $13 \%$ por ano. Este aumento deve-se provavelmente ao fato de, em relação a outras culturas, a produção do girassol apresentar grandes vantagens, como: alta capacidade de adaptação a variações de latitude, longitude e fotoperíodo, alta resistência à seca, insetos e doenças, além de gerar uma melhora nas condições do solo para culturas seguintes (Embrapa, 2010).

Segundo Mandarino (1992), dos óleos vegetais comestíveis, o óleo de girassol é o que apresenta o maior teor porcentual de ácidos graxos poli-insaturados em sua composição, sobretudo de ácido linoleico, essencial ao organismo humano e que deve ser ingerido na dieta. Além disso, o consumo humano de óleo de girassol constitui um importante fator de prevenção de aterosclerose e de problemas no sistema cardiovascular.

As proteínas de sementes de girassol têm bom perfil de aminoácidos essenciais, só os níveis de lisina são baixos. Por isso, o farelo de girassol é, muitas vezes, usado em adição ao farelo de soja, rico em lisina, mas pobre em aminoácidos sulfatados (Carrão-Panizzi e Mandarino, 2005). Além disso, segundo Carrão-Panizzi e Mandarino (2005), o farelo do girassol é uma boa fonte de cálcio, fósforo e vitaminas do complexo B.

A composição de lipídeos varia com a posição da semente no capítulo de girassol (Zimmerman e Fick, 1973), havendo ainda muita divergência entre os autores sobre a região do capítulo que produz sementes maior quantidade de óleos.

Devido ao maior tempo e às melhores condições para a nutrição das sementes da região periférica do capítulo, espera-se que essas sementes apresentem maior quantidade de compostos de reserva do que as das outras regiões. Porém, Castro e Farias (2005) afirmam que sementes formadas na periferia do capítulo são maiores e têm maior peso, porém menor teor de óleo do que as formadas no centro. Já Matthes e Ungaro (1983) concluíram que as sementes da região intermediária do capítulo apresentam maior teor de óleo.

Marcos-Filho (2005) relata que sementes de girassol formadas na região mediana e periférica do capítulo, geralmente possuem maiores teores de óleo e de proteínas em comparação as da região central, que apresentam sementes malformadas devido à nutrição deficiente. Segundo esse mesmo autor, diferentes níveis de competição entre as plantas-mãe também podem influenciar nas reservas armazenadas nas sementes de segunda geração.

Segundo Carvalho e Toledo (1978), uma semente de menor vigor tem menor capacidade e condições de restaurar seus tecidos danificados, e a emergência dessa plântula ocorrerá com atraso em relação à outra de maior vigor. Dessa forma, sementes de baixo vigor apresentam maior tempo inicial, baixa velocidade e baixa sincronia na germinação (Marcos-Filho, 2005).

Sandhu et al. (2006) apresentaram que sementes localizadas na região periférica têm germinação mais rápida, esgotando mais rapidamente os metabólitos dos cotilédones para o melhor desenvolvimento do eixo embrionário em comparação com sementes localizadas nos verticilos centrais do capítulo do girassol.

Brunes (2010) trabalhando com competição intraespecífica, utilizando sementes de girassol de alto e baixo vigor na linha de semeadura, concluiu que comunidades de plantas de girassol provenientes de sementes com diferentes níveis de vigor não apresentam diferenças quanto ao diâmetro e altura dos capítulos; sobrevivência e à produtividade.

Dessa forma, o objetivo desse trabalho foi avaliar a composição química e a qualidade fisiológica de sementes de girassol de diferentes regiões do capítulo de plantas originadas de sementes de alto e baixo vigor, que sofreram competição intraespecífica.

\section{Material e Métodos}

O material experimental foi obtido a partir do experimento conduzido por Brunes (2010), na fazenda experimental do Glória, da Universidade Federal de Uberlândia. Nesse trabalho foi avaliado a interferência da competição intraespecífica na produtividade de populações de plantas do híbrido de girassol Hélio 360, oriundas de parcelas semeadas com diferentes proporções de sementes de alto e baixo vigor na linha de semeadura: 1,00 (1A:1A); 0,75 (3A:1B); 0,67 (2A:1B); 0,50 (1A:1B); 0,33 (1A:2B) e 0,25 (1A:3B) e 0,00 (1B:1B).

Os capítulos da área útil do experimento foram colhidos separando-os de acordo com o vigor das sementes que originaram cada planta da parcela e foram colocados para secar a sombra, sendo debulhadas manualmente, separando cada terço do capítulo (periférico, mediano e central).

Para cada posição do capítulo, o delineamento 
experimental foi em blocos casualizados, com quatro repetições; os tratamentos foram os mesmos, distribuídos em parcelas subdivididas. Nas parcelas, avaliou-se cinco proporções de vigor das sementes utilizadas na semeadura: (3A:1B); (2A:1B); (1A:1B); (1A:2B) e (1A:3B). Nas subparcelas, foram avaliadas as sementes das plantas oriundas de sementes de cada nível de vigor (alto e baixo) e dois tratamentos adicionais (1A:1A e 1B:1B), respectivamente.

Foi avaliada a composição química, determinando-se as porcentagens de proteínas, cinzas, lipídeos, carboidratos totais e de umidade.

A determinação do teor de proteínas foi baseada na determinação de nitrogênio, pelo processo de digestão Kjeldahl. Sendo que para obter-se a porcentagem de proteínas da amostra, a porcentagem de nitrogênio foi multiplicada pelo fator de correção 6,25. A determinação da porcentagem de cinzas foi feita segundo as normas da Farmacopéia Brasileira (Brasil, 1988), com a incineração de $3 \pm 0,5 \mathrm{~g}$ de amostra em mufla a $550{ }^{\circ} \mathrm{C}$ por 2 horas.

A determinação da porcentagem de lipídeos foi feita triturando cinco gramas de sementes em moinho de facas com peneira de $5 \mathrm{~mm}$. Após a trituração, as amostras foram pesadas em balança analítica e colocada em um papel filtro também previamente pesado. O papel filtro foi, então, amarrado com linha de nylon número $0,40 \mathrm{~mm}$ utilizada em pescaria, de forma a deixar a amostra completamente retida no interior do papel. Após, foram colocados $100 \mathrm{~mL}$ de éter de petróleo p.a. em recipiente de vidro com capacidade para $250 \mathrm{~mL}$. As amostras amarradas no papel filtro foram totalmente submergidas no éter de petróleo, o recipiente foi tampado e agitado por 90 minutos a $160 \mathrm{rpm}$ em uma mesa agitadora. Após esse período, os recipientes foram abertos e o recipiente de papel com a amostra foi retirado e torcido manualmente de forma que todo o óleo fosse drenado. Em seguida, colocaram-se os recipientes de vidro abertos ao ar livre e à temperatura ambiente, com o auxílio de ventiladores, para acelerar a evaporação do reagente. Após, os recipientes foram colocados em dessecadores com sílica gel por 48 horas, sendo pesados a seguir em balança analítica, calculando-se a porcentagem de lipídeos pela fórmula:

$$
\% \text { de lipídeos }=\frac{\left(P_{2}-P_{\underline{1}}\right) \times 100}{P A}
$$

Em que:

$\mathrm{P}_{1}=$ peso do recipiente antes da extração

$\mathrm{P}_{2}=$ peso do recipiente depois da extração

PA - peso da amostra de sementes

A determinação do grau de umidade nas amostras foi feita a partir da metodologia prescrita pelas Regras para Análise de Sementes- RAS (Brasil, 2009), utilizando o método da estufa a baixas temperaturas $101-105^{\circ} \mathrm{C}$.

A determinação de carboidratos totais (carboidratos de reserva e carboidratos estruturais) foi feita a partir da fórmula abaixo:

$\%$ de carboidratos totais $=100-(\% L+\% U+\% P+\% C)$

Em que:

$$
\begin{aligned}
& \mathrm{L}=\text { lipídeos } \\
& \mathrm{U}=\text { umidade } \\
& \mathrm{P}=\text { proteína } \\
& \mathrm{C}=\text { Cinzas }
\end{aligned}
$$

Para avaliação da qualidade fisiológica das sementes, foi utilizado o teste de emergência em areia, conduzido na casa de vegetação do Instituto de Ciências Agrárias da Universidade Federal de Uberlândia. Foram utilizadas bandejas plásticas com dimensões de $55 \mathrm{~cm}$ de comprimento, $35 \mathrm{~cm}$ de largura e $9 \mathrm{~cm}$ de profundidade, as quais constituíram as subparcelas. O substrato utilizado foi areia média previamente peneirada e submetida à solarização.

Foram semeadas 200 sementes por subparcela, em oito linhas com 25 sementes, utilizando-se gabaritos para marcação das linhas e para padronização da profundidade de semeadura. Após foram mantidas com umidade de $70 \%$ da capacidade de retenção do substrato, mediante irrigações. A contagem das plântulas emersas foi feita a cada 12 horas $(6 \mathrm{~h}$ e 18 h) durante oito dias, quando a emergência estabilizou. O critério empregado para planta emersa foi o momento em que as mesmas se encontravam completamente eretas em relação ao substrato. Depois de contadas, as plântulas foram seccionadas próximo ao substrato, com auxílio de uma tesoura para que a próxima contagem fosse facilitada. A temperatura mínima e máxima e a umidade relativa do ar da casa de vegetação foram monitoradas por um termômetro de máxima e mínima e um higrômetro, instalados em um abrigo climatológico, próximo às bancadas. De posse dos dados coletados foram determinados, segundo Santana e Ranal (2004), o tempo inicial de emergência $\left(t_{o}\right)$, tempo final de emergência $\left(t_{f}\right)$, tempo médio de emergência $(\mathrm{t})$, emergência (E), coeficiente de variação do tempo (CVt), velocidade média $(v)$, incerteza $(I)$, sincronia $(Z)$ e velocidade de emergência (Ve).

Os dados de cada posição do capítulo foram analisados com recursos do software Sisvar. Também foi usado o programa Assistat, em que foram analisadas as proporções de vigor e os níveis de vigor em fatorial, junto com os dois tratamentos adicionais. Para análise em parcelas 
subdivididas com os dois adicionais, foram associados manualmente os dois resultados obtidos em cada programa. Para comparar as sementes oriundas dos terços periférico, mediano e central do capítulo, foi usado o programa Assistat, considerando-se a análise em parcelas subdivididas, em que nas parcelas foram analisados os tratamentos (proporção de vigor e níveis de vigor) e nas subparcelas, os terços do capítulo (periférico, mediano e central).

As diferenças entre as médias dos tratamentos foram comparadas pelo teste de Tukey a 5\% de significância; quando não foram detectadas as diferenças significativas indicadas pelo teste de $\mathrm{F}$, aplicou-se o teste de Duncan a 5\% de significância. A comparação entre todos os tratamentos (incluindo os tratamentos adicionais) foi feita com uso de contrastes ortogonais.

\section{Resultados e Discussões}

Observa-se que apenas as sementes do terço periférico do capítulo das plantas oriundas de sementes com baixo vigor, semeadas nas proporções 2A:1B e 1A:1B apresentaram menor teor de carboidratos do que as sementes dos demais tratamentos (Tabela 1). Quanto à proteína, somente as sementes das plantas oriundas de sementes com alto vigor semeadas na proporção $1 \mathrm{~A}: 2 \mathrm{~B}$ e os adicionais (1A:1A e 1B:1B) apresentaram os menores valores. Além disso, tanto as sementes do terço mediano quanto às do terço central do capítulo das plantas oriundas somente de sementes com alto vigor (1A:1A), apresentaram menor grau de umidade do que as sementes das plantas oriundas somente de sementes com baixo vigor (1B:1B) (Tabela 1).

Tabela 1. Média dos dados, em porcentagem, referentes ao teor de carboidratos (Ch), umidade (U) e proteínas (Pt) das sementes oriundas dos terços dos capítulos de girassol, em função da proporção de vigor das sementes utilizadas na semeadura e do vigor da semente de origem ${ }^{1}$.

\begin{tabular}{cccccc}
\hline \multirow{2}{*}{$\begin{array}{c}\text { Proporções de vigor } \\
\text { (tratamentos) }\end{array}$} & Vigor & Periférico & Mediano & \multicolumn{2}{c}{ Central } \\
\cline { 3 - 6 } & & $\mathrm{Ch}$ & $\mathrm{U}$ & $\mathrm{Pt}$ & $\mathrm{U}$ \\
\cline { 3 - 6 } & & $31,36 \mathrm{a}$ & 6,36 & $22,20 \mathrm{a}$ & 6,54 \\
3A:1B & $32,11 \mathrm{a}$ & 6,28 & $21,71 \mathrm{a}$ & 6,09 \\
2A:1B & Alto & $32,77 \mathrm{a}$ & 6,43 & $22,37 \mathrm{a}$ & 6,30 \\
1A:1B & & $33,07 \mathrm{a}$ & 6,65 & $20,56 \mathrm{~b}$ & 6,52 \\
1A:2B & $34,27 \mathrm{a}$ & 6,62 & $21,66 \mathrm{a}$ & 6,74 \\
\hline 1A:3B & & $31,69 \mathrm{a}$ & 6,46 & $22,31 \mathrm{a}$ & 6,53 \\
\hline 3A:1B & $30,37 \mathrm{~b}$ & 6,21 & $22,53 \mathrm{a}$ & 6,16 \\
2A:1B & $30,49 \mathrm{~b}$ & 6,36 & $21,66 \mathrm{a}$ & 6,42 \\
1A:1B & Baixo & $33,53 \mathrm{a}$ & 6,62 & $21,55 \mathrm{a}$ & 6,47 \\
1A:2B & & $32,85 \mathrm{a}$ & 6,72 & $21,93 \mathrm{a}$ & 6,65 \\
1A:3B & & $35,78 \mathrm{a}$ & $6,33 \mathrm{~b}$ & $19,69 \mathrm{~b}$ & $6,19 \mathrm{~b}$ \\
\hline 1A:1A & Alto & $34,11 \mathrm{a}$ & $6,76 \mathrm{a}$ & $21,16 \mathrm{~b}$ & $6,61 \mathrm{a}$ \\
\hline 1B:1B & Baixo & & &
\end{tabular}

${ }^{1}$ Médias seguidas por uma mesma letra minúscula na coluna, não diferem significativamente, pela comparação das médias dos tratamentos por contrastes ortogonais e pela comparação das médias dos tratamentos adicionais pelo teste de Tukey, ambas a 5\% de probabilidade.

A variável peso de mil sementes apresentou interação entre proporção de vigor e vigor das sementes de origem, para as sementes dos terços mediano e central do capítulo. A comparação entre médias para essa variável está apresentada na Tabela 2. Observa-se que, para as sementes das plantas oriundas de sementes com alto vigor, tanto no terço mediano quanto no central do capítulo, os maiores valores de peso de mil sementes foram observados para o tratamento $3 \mathrm{~A}: 1 \mathrm{~B}$ e os menores valores foram observados no tratamento $1 \mathrm{~A}: 3 \mathrm{~B}$. Para as sementes das plantas oriundas de sementes com baixo vigor, somente houve diferenças significativas para as sementes do terço central do capítulo, no qual o maior valor foi observado no tratamento $2 \mathrm{~A}: 1 \mathrm{~B}$ e o menor valor no tratamento $1 \mathrm{~A}: 2 \mathrm{~B}$.

Nota-se que houve um prejuízo para o acúmulo de reserva nas sementes das plantas oriundas das sementes em menor proporção na linha de semeadura. Assim, 
pode-se inferir que houve competição entre plantas dependendo da proporção de vigor, sobressaindo àquelas colocadas em maior proporção, independentemente de serem de alto ou de baixo vigor. No caso, em sementes das plantas oriundas de sementes com alto vigor da proporção $3 \mathrm{~A}: 1 \mathrm{~B}$, que estavam em maior quantidade na linha de semeadura, apresentaram maior peso de mil sementes. Em contrapartida, as sementes das plantas oriundas de sementes com alto vigor, porém na proporção $1 \mathrm{~A}: 3 \mathrm{~B}$, que estavam em menor quantidade na linha de semeadura, apresentaram menor peso de mil sementes. Sugere-se, dessa forma, que plantas oriundas de sementes com vigor semelhante quando em maior proporção na linha de semeadura, prejudica o desenvolvimento das plantas oriundas de sementes com outro nível de vigor independentemente de ser alto ou baixo.

Pelos dados apresentados na Tabela 3, observa-se que as sementes do terço periférico dos capítulos, apresentam maiores valores para o peso de mil sementes, a umidade e o teor de carboidratos. Já os teores de lipídeos, proteínas e cinzas foram maiores nas sementes do terço central, enquanto que as sementes do terço mediano apresentaram valores intermediários.

O maior peso das sementes do terço periférico dos capítulos, em detrimento das sementes do terço central, é uma característica visível e claramente perceptível, que foi confirmada pela avaliação do peso de mil sementes. Quanto aos lipídeos, por serem compostos hidrofóbicos, é explicável a relação antagônica apresentada entre os teores de umidade e de lipídeos. Nota-se na Tabela 3, que as sementes do terço periférico do capítulo apresentaram baixo teor de lipídeos e maior grau de umidade, sendo que nas sementes do terço central, com maior teor de lipídeos, o grau de umidade foi menor.

Tabela 2. Média dos dados, em gramas, referentes ao peso de mil sementes das sementes dos terços mediano e central dos capítulos de girassol, em função da proporção de vigor das sementes utilizadas na semeadura e do vigor da semente de origem ${ }^{1}$.

\begin{tabular}{|c|c|c|}
\hline \multirow{3}{*}{$\begin{array}{l}\text { Proporção de } \\
\text { vigor }\end{array}$} & \multicolumn{2}{|c|}{ Vigor da semente de origem } \\
\hline & Alto & Baixo \\
\hline & \multicolumn{2}{|c|}{ Terço mediano } \\
\hline $3 \mathrm{~A}: 1 \mathrm{~B}$ & $57,0122 \mathrm{aA}$ & $52,2928 \mathrm{AA}$ \\
\hline $2 \mathrm{~A}: 1 \mathrm{~B}$ & $53,5157 \mathrm{abA}$ & 55,8829 AA \\
\hline $1 \mathrm{~A}: 1 \mathrm{~B}$ & $53,8475 \mathrm{abA}$ & 56,6282 AA \\
\hline $1 \mathrm{~A}: 2 \mathrm{~B}$ & $55,5872 \mathrm{abA}$ & 51,4438 AA \\
\hline $1 \mathrm{~A}: 3 \mathrm{~B}$ & $46,3044 \mathrm{cB}$ & $52,4263 \mathrm{AA}$ \\
\hline $1 \mathrm{~A}: 1 \mathrm{~A}$ & $50,1563 \mathrm{~b}$ & --- \\
\hline \multirow[t]{2}{*}{ 1B:1B } & --- & $50,2378 \mathrm{~A}$ \\
\hline & \multicolumn{2}{|c|}{ Terço central } \\
\hline $3 \mathrm{~A}: 1 \mathrm{~B}$ & 49,4978 aA & $42,1787 \mathrm{AbB}$ \\
\hline $2 \mathrm{~A}: 1 \mathrm{~B}$ & $44,3644 \mathrm{abA}$ & 47,1546 AA \\
\hline $1 \mathrm{~A}: 1 \mathrm{~B}$ & $43,3304 \mathrm{abA}$ & $45,9479 \mathrm{AbA}$ \\
\hline $1 \mathrm{~A}: 2 \mathrm{~B}$ & $46,5660 \mathrm{abA}$ & $40,2135 \mathrm{BB}$ \\
\hline $1 \mathrm{~A}: 3 \mathrm{~B}$ & $39,1522 \mathrm{cB}$ & $45,4872 \mathrm{AbA}$ \\
\hline $1 \mathrm{~A}: 1 \mathrm{~A}$ & $42,5634 \mathrm{bc}$ & --- \\
\hline $1 \mathrm{~B}: 1 \mathrm{~B}$ & --- & $41,6154 \mathrm{Ab}$ \\
\hline
\end{tabular}

${ }^{1}$ Médias seguidas por letras minúsculas nas colunas e maiúsculas nas linhas iguais indicam que não há diferença significativa entre os tratamentos pelo teste de Duncan a 5\% de probabilidade

Tabela 3. Média dos dados, em gramas, referentes ao peso de mil sementes e porcentagens de umidade, lipídeos, proteínas, cinzas e carboidratos nas sementes de girassol, em função da posição das sementes no capítulo. ${ }^{1}$

\begin{tabular}{ccccccc}
\hline $\begin{array}{c}\text { Posição no } \\
\text { capítulo }\end{array}$ & $\begin{array}{c}\text { Peso de mil } \\
\text { sementes }\end{array}$ & Umidade $^{2}$ & Lipídeos $^{4}$ & Proteína $^{2}$ & Cinzas $^{2}$ & Carboidratos $^{2}$ \\
\hline Periférica & $63,11 \mathrm{a}$ & $6,63 \mathrm{a}$ & $37,39 \mathrm{~b}$ & $20,37 \mathrm{~b}$ & $3,20 \mathrm{~b}$ & $32,41 \mathrm{a}$ \\
Mediana & $52,94 \mathrm{~b}$ & $6,48 \mathrm{~b}$ & $38,53 \mathrm{~b}$ & $20,84 \mathrm{ab}$ & $3,12 \mathrm{~b}$ & $31,03 \mathrm{~b}$ \\
Central & $44,01 \mathrm{c}$ & $6,44 \mathrm{~b}$ & $38,70 \mathrm{a}$ & $21,26 \mathrm{a}$ & $3,42 \mathrm{a}$ & $30,18 \mathrm{~b}$ \\
\hline
\end{tabular}

${ }^{1} \mathrm{Na}$ coluna, as médias seguidas por uma mesma letra não diferem estatisticamente;

${ }^{2}$ Comparadas pelo teste de Tukey a $5 \%$ de probabilidade.

${ }^{3}$ Peso corrigido para grau de umidade de $10 \%$.

${ }^{4}$ Comparadas pelo teste de Duncan a $5 \%$ de probabilidade

Segundo Castro e Farias (2005) sementes formadas na periferia do capítulo são maiores e têm maior peso, porém menor teor de óleo do que as formadas no centro. Assim, as sementes maiores da região periférica têm maior volume e superfície de casca e uma diminuição do volume da amêndoa, o que gera um teor menor de óleo do que as sementes menores formadas na região central.

De acordo com Carrão-Panizzi e Mandarino (2005), as 
sementes de girassol podem ser classificadas em dois tipos: sementes não oleosas, que são maiores, com coloração rajada e que apresentam casca mais fibrosa (40 - 45\% de casca e 25 - 30\% de óleo); e sementes oleosas, que são menores, com coloração preta e cascas bem aderidas (20$30 \%$ de casca). Castro e Farias (2005) afirmam que há uma relação negativa entre a proporção de casca e o teor de óleo das sementes de girassol. Dessa forma, sementes com casca grossa, de coloração clara ou clara estriada apresentam menor teor de óleo, enquanto que sementes de casca com coloração negra ou negra estriada apresentam maiores teores de óleo.

Com relação aos carboidratos, Munshi et al. (2003), que em sua metodologia desconsideram as cascas das sementes, afirmam que sementes da região periférica do capítulo de girassol têm conteúdo de carboidratos menor do que as sementes da região central. Dessa forma, o alto teor de carboidratos totais observado nas sementes do terço periférico do capítulo, neste estudo pode ser atribuído ao alto teor de fibras dessas sementes, já que a variável carboidratos totais analisada incluiu carboidratos de reserva e estruturais, uma vez que a casca não foi desconsiderada. Apesar do alto teor de fibras das sementes do terço periférico do capítulo, os carboidratos de reserva devem também estar em altas concentrações nessas sementes, sendo o principal composto de reserva energética. Já nas sementes do terço central, o principal composto de reserva energética devem ser os lipídeos, seguido por proteínas, que participam também do processo enzimático nas sementes.

Divergindo dos resultados obtidos nesse trabalho, Matthes e Ungaro (1983) comparando a posição no capítulo com os teores de óleo e umidade de sementes de girassol, concluíram que as sementes da região intermediária do capítulo apresentam maior teor de óleo e que não houve diferença nos graus de umidade entre sementes das diferentes regiões do capítulo.

Já, Munshi et al. (2003) e Gupta et al. (2009) afirmam em seus trabalhos que as sementes do terço periférico apresentam maior produção de óleo do que as demais sementes do capítulo. Ambos os autores atribuem esse fato ao maior espaço no verticilo para desenvolvimento das sementes periféricas, facilitando o rápido enchimento de óleo e, em detrimento das sementes de regiões mais centrais do capítulo.

Maeda et al. (1987) relacionaram em seu trabalho aspectos da qualidade e da composição química de sementes de girassol oriundas de três regiões do capítulo com diferentes períodos de florescimento. Os resultados desse trabalho demonstraram que com até 20 dias após o florescimento, as sementes da região periférica do capítulo apresentam maior conteúdo de óleo com relação às sementes das regiões mediana e central. Após os 20 dias de florescimento, há uma inversão nesse padrão, passando as sementes centrais a apresentar maiores porcentagens de óleo. A porcentagem de óleo, segundo os autores somente estabiliza a partir de 30 dias após o florescimento.

Segundo Mandarino (1992), estudos bioquímicos sobre a variação quantitativa e qualitativa do conteúdo de óleo e proteína nas sementes de girassol demonstraram que a biossíntese da fração lipídica inicia-se no final do período de florescimento e prolonga-se durante todo o processo de enchimento de grãos. Já a biossíntese proteica ocorre durante a fase vegetativa e se mantém constante durante as diferentes fases de desenvolvimento das sementes.

Dessa forma, a divergência de resultados a respeito do teor de óleo das sementes em diferentes terços do capítulo de girassol pode ser devido a diferenças nas épocas em que a composição química das sementes foi analisada.

Alguns trabalhos (Pustavoit; Djakov, 1972 apud Radic et al., 2009; Djakov, 1980 apud Radic et al., 2009; Tavoljanskiy et al., 2004) afirmam a existência de um antagonismo entre a síntese de lipídeos e de proteínas em sementes de girassol. Já Djakov (1986) apud Radic et al. (2009) negou esse antagonismo. Nesse estudo não foi encontrado antagonismo entre a composição química desses dois compostos nos terços do capítulo, de forma que tanto proteínas como lipídeos apresentam maiores teores no terço central.

Os dados médios referentes aos tempos inicial e médio, velocidades média e de emergência e emergência são apresentados na Tabela 4. Observa-se que os tratamentos adicionais diferiram significativamente quanto à emergência somente para as sementes oriundas do terço mediano dos capítulos, sobressaindo as das plantas provenientes de sementes com alto vigor (1A:1A). O mesmo ocorreu com tempo inicial, porém para as sementes do terço central dos capítulos. A emergência apresentou alterações significativas somente nas sementes oriundas do terço mediano, apresentando menores valores para os tratamentos $2 \mathrm{~A}: 1 \mathrm{~B}$ e 1A:1B para as sementes das plantas oriundas de semente com alto vigor e 1A:3B para sementes das plantas oriundas de sementes com baixo vigor. Nota-se que os valores de incerteza das sementes dos terços periférico e mediano foram, em geral, maiores quando se reduziu a quantidade de sementes com alto vigor na proporção de semeadura. A sincronia foi alterada significativamente somente pelos tratamentos adicionais, apenas quando as sementes foram provenientes do terço periférico, sobressaindo as das 
plantas oriundas de sementes de alto vigor.

A variável tempo final apresentou interação entre a proporção de vigor e o vigor das sementes de origem, cujos resultados são apresentados na Tabela 5. Nota-se que, para as sementes provenientes do terço central do capítulo, o maior valor de tempo final de emergência foi apresentado pelo tratamento $2 \mathrm{~A}: 1 \mathrm{~B}$ quando obtidas das plantas de sementes com alto vigor, diferindo significativamente das obtidas de plantas oriundas de sementes com baixo vigor que concluíram a emergência em menor tempo.

Tabela 4. Média dos dados, em porcentagem, referentes incerteza ( $I)$ (bit), sincronia $(Z)$, emergência $(E)$ (\%) e tempo inicial (Ti) (horas) das sementes oriundas dos terços dos capítulos de girassol, em função da proporção de vigor das sementes utilizadas na semeadura e do vigor da semente de origem. ${ }^{1}$

\begin{tabular}{|c|c|c|c|c|c|c|}
\hline \multirow{3}{*}{$\begin{array}{l}\text { Proporções de vigor } \\
\text { (tratamentos) }\end{array}$} & \multirow{3}{*}{ Vigor } & \multicolumn{5}{|c|}{ Terços } \\
\hline & & \multicolumn{2}{|c|}{ Periférico } & \multicolumn{2}{|c|}{ Mediano } & \multirow{2}{*}{$\begin{array}{r}\text { Central } \\
T i\end{array}$} \\
\hline & & $I$ & $Z$ & $I$ & $E$ & \\
\hline $3 \mathrm{~A}: 1 \mathrm{~B}$ & \multirow{5}{*}{ Alto } & $1,82 \mathrm{a}$ & 0,3401 & $1,82 \mathrm{~b}$ & $99,75 \mathrm{a}$ & 84 \\
\hline $2 \mathrm{~A}: 1 \mathrm{~B}$ & & $1,84 \mathrm{a}$ & 0,3520 & $2,04 \mathrm{a}$ & $97,50 \mathrm{~b}$ & 87 \\
\hline $1 \mathrm{~A}: 1 \mathrm{~B}$ & & $1,78 \mathrm{a}$ & 0,3592 & $1,95 \mathrm{a}$ & $97,75 \mathrm{~b}$ & 93 \\
\hline $1 \mathrm{~A}: 2 \mathrm{~B}$ & & $1,81 \mathrm{a}$ & 0,3297 & $2,02 \mathrm{a}$ & $98,00 \mathrm{a}$ & 84 \\
\hline $1 \mathrm{~A}: 3 \mathrm{~B}$ & & $1,85 \mathrm{a}$ & 0,3474 & $1,79 \mathrm{~b}$ & $100,00 \mathrm{a}$ & 93 \\
\hline $3 \mathrm{~A}: 1 \mathrm{~B}$ & \multirow{5}{*}{ Baixo } & $1,79 \mathrm{a}$ & 0,3588 & $1,78 \mathrm{~b}$ & $99,50 \mathrm{a}$ & 87 \\
\hline $2 \mathrm{~A}: 1 \mathrm{~B}$ & & $1,48 \mathrm{~b}$ & 0,4649 & $1,70 \mathrm{~b}$ & $100,00 \mathrm{a}$ & 87 \\
\hline $1 \mathrm{~A}: 1 \mathrm{~B}$ & & $1,73 \mathrm{a}$ & 0,3698 & $1,91 \mathrm{a}$ & $99,00 \mathrm{a}$ & 90 \\
\hline $1 \mathrm{~A}: 2 \mathrm{~B}$ & & $1,81 \mathrm{a}$ & 0,3537 & $1,85 \mathrm{a}$ & $98,75 \mathrm{a}$ & 90 \\
\hline $1 \mathrm{~A}: 3 \mathrm{~B}$ & & $1,74 \mathrm{a}$ & 0,3879 & $1,73 \mathrm{~b}$ & $97,50 \mathrm{~b}$ & 90 \\
\hline $1 \mathrm{~A}: 1 \mathrm{~A}$ & Alto & $1,70 \mathrm{a}$ & $0,3884 \mathrm{a}$ & $1,81 \mathrm{~b}$ & $98,25 \mathrm{a}$ & $96 \mathrm{a}$ \\
\hline 1B:1B & Baixo & $1,94 \mathrm{a}$ & $0,3080 \mathrm{~b}$ & $1,80 \mathrm{~b}$ & $96,25 \mathrm{~b}$ & $87 \mathrm{~b}$ \\
\hline
\end{tabular}

${ }^{1}$ Médias seguidas por letras maiúsculas iguais na coluna indicam que não há diferença significativa entre os tratamentos pelo teste de Duncan a $5 \%$ de probabilidade.

Tabela 5. Média dos dados, em horas, referentes ao tempo final de emergência das sementes oriundas do terço central dos capítulos de girassol, em função da proporção de vigor das sementes utilizadas na semeadura e do vigor da semente de origem, pelo teste de emergência em areia. ${ }^{1}$

\begin{tabular}{ccccc}
\hline \multirow{2}{*}{$\begin{array}{c}\text { Proporção de } \\
\text { vigor }\end{array}$} & \multicolumn{4}{c}{ Vigor da semente de origem } \\
\cline { 2 - 5 } & \multicolumn{4}{c}{ Alto } \\
\multicolumn{4}{c}{ Terço central } \\
\cline { 2 - 5 } 3A:1B & 153 & abA & 159 & $\mathrm{aA}$ \\
2A:1B & 162 & $\mathrm{aA}$ & 147 & $\mathrm{bB}$ \\
$1 \mathrm{~A}: 1 \mathrm{~B}$ & 156 & $\mathrm{abA}$ & 147 & $\mathrm{bA}$ \\
$1 \mathrm{~A}: 2 \mathrm{~B}$ & 150 & $\mathrm{bA}$ & 159 & $\mathrm{aA}$ \\
$1 \mathrm{~A}: 3 \mathrm{~B}$ & 159 & $\mathrm{abA}$ & 153 & $\mathrm{abA}$ \\
1A:1A & 156 & $\mathrm{ab}$ & --- & \\
1B:1B & --- & & 156 & $\mathrm{ab}$ \\
\hline
\end{tabular}

${ }^{1}$ Médias seguidas por letras minúsculas nas colunas e maiúsculas nas linhas iguais indicam que não há diferença significativa entre os tratamentos pelo teste de Duncan a $5 \%$ de probabilidade.
Pelos dados médios apresentados na Tabela 6, constata-se que as sementes do terço periférico do capítulo apresentaram menor tempo final e coeficiente de variação do tempo de emergência e maiores tempos inicial e médio e sincronia de emergência. As sementes do terço central apresentam resultados opostos aos das sementes periféricas e as sementes medianas apresentam resultados intermediários.

Pelos gráficos da frequência relativa de emergência das sementes dos tratamentos (dados não apresentados), observa-se que, de modo geral, independentemente a da proporção de sementes de alto e baixo vigor utilizadas na semeadura, as sementes do terço periférico apresentam um pico de emergência mais acentuado e concentrado em poucas horas, demonstrando maior homogeneidade e sincronia de emergência, ao contrário das sementes do terço central. Também se pode observar que as sementes das plantas oriundas de sementes com alto vigor, geralmente, apresentaram um pico de emergência mais acentuado com maior homogeneidade. 
Tabela 6. Média dos dados referentes ao tempo inicial (Ti) (horas), tempo final (Tf) (horas), tempo médio ( $T m$ ) (horas), coeficiente de variação do tempo $(C V t)(\%)$ e sincronia $(Z)$ das sementes de girassol, em função da posição das sementes no capítulo.

\begin{tabular}{cccccc}
\hline Posição no capítulo & $T i$ & $T f$ & $T m$ & $C V t$ & $Z$ \\
\hline Periférica & $91,75 \mathrm{a}$ & $151,50 \mathrm{~b}$ & $115,33 \mathrm{a}$ & $9,54 \mathrm{~b}$ & $0,36 \mathrm{a}$ \\
Mediana & $91,75 \mathrm{a}$ & $153,25 \mathrm{ab}$ & $114,65 \mathrm{ab}$ & $9,98 \mathrm{~b}$ & $0,34 \mathrm{a}$ \\
Central & $89,00 \mathrm{~b}$ & $155,00 \mathrm{a}$ & $113,29 \mathrm{~b}$ & $10,68 \mathrm{a}$ & $0,32 \mathrm{~b}$ \\
\hline
\end{tabular}

${ }^{1} \mathrm{Na}$ coluna, as médias seguidas pela mesma letra não diferem estatisticamente entre si. Foi aplicado o teste de Tukey a 5\% de probabilidade.

A Tabela 7 apresenta a média dos dados de incerteza da emergência dos tratamentos, que apresentou interação entre as proporções de vigor e o terço do capítulo. Assim, para as sementes das plantas oriundas de sementes com alto vigor do tratamento $1 \mathrm{~A}: 1 \mathrm{~B}$, a maior incerteza foi obtida para as sementes do terço central do capítulo e a menor no terço mediano. Já nas sementes das plantas oriundas de sementes com baixo vigor dos tratamentos $1 \mathrm{~A}: 2 \mathrm{~B}$ e 1A:3B, a maior incerteza foi obtida com sementes do terço periférico dos capítulos e a menor do terço central. Com esses resultados, observa-se que a incerteza no processo de emergência das sementes é influenciada pela proporção de vigor das sementes na linha de semeadura das plantas de origem.

Tabela 7. Média dos dados, em bit, referentes à incerteza de emergência de sementes de girassol, em função da proporção de vigor das sementes utilizadas na semeadura e da posição das sementes no capítulo ${ }^{1}$.

\begin{tabular}{ccccc}
\hline \multicolumn{2}{c}{ Tratamentos } & \multicolumn{3}{c}{ Posição no capítulo } \\
\hline Vigor da semente de origem & Proporção de vigor & Periférica & Mediana & Central \\
\hline \multirow{3}{*}{ Alto } & $3 \mathrm{~A}: 1 \mathrm{~B}$ & $1,71 \mathrm{aA}$ & $1,81 \mathrm{aA}$ & $1,89 \mathrm{aA}$ \\
& $2 \mathrm{~A}: 1 \mathrm{~B}$ & $1,84 \mathrm{aA}$ & $2,04 \mathrm{aA}$ & $2,03 \mathrm{aA}$ \\
& $1 \mathrm{~A}: 1 \mathrm{~B}$ & $1,81 \mathrm{aAB}$ & $2,02 \mathrm{aB}$ & $1,68 \mathrm{aA}$ \\
& $1 \mathrm{~A}: 2 \mathrm{~B}$ & $1,79 \mathrm{aA}$ & $1,78 \mathrm{aA}$ & $1,80 \mathrm{aA}$ \\
& $1 \mathrm{~A}: 3 \mathrm{~B}$ & $1,73 \mathrm{aA}$ & $1,91 \mathrm{aA}$ & $1,89 \mathrm{aA}$ \\
\hline \multirow{2}{*}{ Baixo } & $3 \mathrm{~A}: 1 \mathrm{~B}$ & $1,82 \mathrm{aA}$ & $1,82 \mathrm{aA}$ & $1,85 \mathrm{aA}$ \\
& $2 \mathrm{~A}: 1 \mathrm{~B}$ & $1,78 \mathrm{aA}$ & $1,95 \mathrm{aA}$ & $2,03 \mathrm{aA}$ \\
& $1 \mathrm{~A}: 1 \mathrm{~B}$ & $1,85 \mathrm{aA}$ & $1,79 \mathrm{aA}$ & $1,85 \mathrm{aA}$ \\
& $1 \mathrm{~A}: 2 \mathrm{~B}$ & $1,48 \mathrm{aA}$ & $1,70 \mathrm{aAB}$ & $1,84 \mathrm{aB}$ \\
\multirow{2}{*}{ Tratamentos adicionais } & $1 \mathrm{~A}: 3 \mathrm{~B}$ & $1,81 \mathrm{aA}$ & $1,85 \mathrm{aAB}$ & $2,07 \mathrm{aB}$ \\
\hline
\end{tabular}

${ }^{1}$ Médias seguidas por letras minúsculas nas colunas e maiúsculas nas linhas iguais indicam que não há diferença significativa entre os tratamentos pelo teste de Tukey a $5 \%$ de probabilidade.

Silveira et al. (2005) afirmam que sementes com alto teor de óleo têm mais problemas de germinação, principalmente em temperaturas mais amenas de solo. Esse dado pode ser justificado pelo fato de que a via metabólica de catálise de lipídeos é mais lenta e mais complexa do que a via dos carboidratos, envolvendo a transformação de lipídeos em açucares pela gliconeogênese.

Munshi et al. (2003) indicam que para produção de grãos de girassol destinados a extração de óleo, principalmente para consumo humano, deve-se utilizar sementes com alto conteúdo de óleo e baixa concentração de carboidratos. Já para a produção de sementes, segundo esses autores, a utilização de sementes maiores e com maiores quantidades de carboidratos para facilitar a germinação das sementes. Assim, se o objetivo foi a homogeneidade de estande é mais favorável à utilização de sementes com alto conteúdo de carboidratos, que emergem com maior sincronia.

Assim, as sementes do terço periférico que apresentaram como principal fonte de reserva energética os carboidratos, provavelmente, adquiriram energia para o desenvolvimento do eixo embrionário de forma mais simples e homogênea entre as sementes. Portanto, no processo de produção de sementes, deve-se adequar um processo de seleção 
para descartar as sementes dos terços mediano e central, principalmente as do terço central.

\section{Conclusões}

A proporção de vigor das sementes na linha de semeadura interfere no desempenho das plantas e na qualidade das sementes resultantes, sendo que as plantas oriundas de sementes colocadas em maior proporção na linha, independentemente do vigor têm maior competitividade.

A composição química das sementes de girassol variou com a posição das sementes no capítulo. Maior teor de carboidratos e peso de mil sementes, foi observado no terço periférico, ao passo que maior teor de proteína e lipídeos foi obtido das sementes do terço central.

A posição da semente no capítulo interferiu nas variáveis da germinação. As sementes do terço periférico do capítulo de girassol, apesar de apresentarem maior tempo inicial de emergência em areia, apresentam menor tempo final e menor coeficiente de variação do tempo, tendo maior homogeneidade e sincronia de emergência.

As sementes do terço central, em contrapartida apresentam menor homogeneidade e sincronia de emergência, sendo mais distribuída no tempo.

\section{Referências}

BRASIL. Ministério da Saúde. Farmacopéia Brasileira. 4. ed., São Paulo: Atheneu, 1988.

BRASIL. Ministério da Agricultura, Pecuária e Abastecimento. Regras para análise de sementes. Ministério da Agricultura, Pecuária e Abastecimento. Secretaria de Defesa Agropecuária. Brasília: MAPA/ACS, 2009. 395p. http://www.agricultura.gov.br/arq_editor/file/Laborat $\%$ C3\%B3rio/ Sementes/Regras\%20para\%20Analise\%20de\%20Sementes.pdf

BRUNES, R.R. Desempenho de híbrido de girassol em resposta ao vigor das sementes, população de plantas e desuniformidade de semeadura no outono de 2009 em Uberlândia - MG. 2010. 41f. Dissertação (Mestrado em Agronomia/Fitotecnia) - Instituto de Ciências Agrárias, Universidade Federal de Uberlândia, Uberlândia. http://buscatextual.cnpq.br/ buscatextual/visualizacv.jsp?id=K4137367Z2

CARRÃO-PANIZZI, M.C.; MANDARINO, J.M.G. Produtos protéicos do girassol. In: LEITE, R. M.V.B.C.; BRIGHENTI, A.M.; CASTRO, C. (Ed.) Girassol do Brasil. Londrina: Embrapa Soja, 2005. cap.4, p.51-68.

CARVALHO, N.M.; TOLEDO, F.F. Relationships between available space for plant development and seed vigour in peanut (Arachishypogaea) plant performance. Seed Science and Technology, v.6, n.4, p.907-1110, 1978.

CASTRO, C.; FARIAS, J.R.B. Ecofisiologia do girassol. In: LEITE,
R.M.V. B.C.; BRIGHENTI, A.M.; CASTRO, C. (Eds.). Girassol do Brasil. Londrina: Embrapa Soja, 2005. cap.9, p.163-218.

EMBRAPA. Centro Nacional de Pesquisa de Soja. Girassol. Londrina, 2010. http://www.cnpso.embrapa.br/index.php?op_page=55\&cod_pai=39

GUPTA, R.; SHARMA, S.; MUNSHI, S.K. Physical characteristics and biochemical composition of seed influenced by their position in different whorls of sunflower head-effect of storage. Helia, v.32, n.50, p.135144, 2009. http://www.doiserbia.nb.rs/img/doi/1018-1806/2009/101818060950135G.pdf

MAEDA, J.A.; UNGARO, M.R.G.; LAGO, A.A.; RAZERA, L.F. Estádio de maturação e qualidade de sementes de girassol. Bragantia, v.46, n.1, p.35-44, 1987. http://www.scielo.br/pdf/brag/v46n1/05.pdf

MANDARINO, J.M.G. Características bioquímicas e nutricionais do óleo e do farelo de girassol. Londrina: EMBRAPA-CNPSO, 1992. 25p. (Embrapa-CNPSo. Documentos, 52).

MARCOS-FILHO, J. Fisiologia de sementes de plantas cultivadas. Piracicaba: FEALQ, 2005. 495p.

MATTHES, L.A.F.; UNGARO, M.R.G. Influência da localização da semente na porcentagem de óleo e no teor de umidade em capítulos de girassol. Bragantia, v.42, p.239-244, 1983. http://www.scielo.br/scielo. php?pid=S0006-87051983000100022\&script $=$ sci_arttext

MUNSHI, S.K.; KAUSHAL, B.; BAJAJ, R.K. Compositional changes in seeds influenced by their positions in different whorls of mature sunflower head. Journal of the Science of Food and Agriculture, v.83, p.1622-1626, 2003.

RADIC, V.; VUJAKOVIC, M.; MARJANOVIC-JEROMELA, A.; MRDA, J.; MIKLIC, V.; DUSANIC, N.; BALALIC, I. Interdependence of sunflower seed quality parameters. Helia, v.32, n.50, p.157-164, 2009. http://www. doiserbia.nb.rs/img/doi/1018-1806/2009/1018-18060950157R.pdf

SANDHU, S.; SHARMA, S.; MUNSHI, S.K. Metabolic changes in fast and slow germinating sunflower (Helianthus annuus L.) seeds. Indian Journal of Agricultural Biochemistry, v.19, p.15-18, 2006.

SANTANA, D.G.; RANAL, M.A. Análise da germinação: um enfoque estatístico. Brasília: Editora UnB, 2004. 247p.

SILVEIRA, J.M.; CASTRO, C.; MESQUITA, C.M.; PORTUGAL, F.A.F. Semeadura e manejo da cultura de girassol. In: LEITE, R.M.V.B.C.; BRIGHENTI, A.M.; CASTRO, C. (Ed.) Girassol do Brasil. Londrina: Embrapa Soja, 2005. cap.14, p.376-409.

TAVOLJANSKIY, N.P.; CHIRYAEV， P.V.; SCHERSTYUK， S.V.; ALTINNIKOVA, V.I.; TIKHOMIROV, V.T. Development of original material for sunflower breeding for seed characteristics, oil and protein quality in the conditions of central-chernozem. Helia, v.27, n.40, p.117122, 2004. http://www.doiserbia.nb.rs/img/doi/1018-1806/2004/101818060440117T.pdf

ZIMMERMAN, D.C.; FICK, G.N. Fatty acid composition of sunflower (Helianthus annuus L.) oil as influenced by seed position. Journal of the American Oil Chemist's Society, v.50, p.273-275, 1973. 